\title{
Prevalence of Bronchial Asthma among School Aged Children in Elmaraghah Center in Sohag Governorate
}

\author{
ABDELAKHER A. RASHIED, M.Sc.*; MOHAMMED M. ABDEL SALAM, M.D.*; \\ SAFAA A. ELNAGGAR, M.D.** and DINA M. SHOKRY, M.D.* \\ The Departments of Pediatrics* and Community Medicine**, Faculty of Medicine, Zagazig University
}

\begin{abstract}
Background: Asthma and wheezes are the most common acute and chronic diseases in childhood. Early detection and good management of asthma is very important to reduce the risk and improve the health status of the diseased children.

Aim of Study: Is estimation of asthma prevalence among school-aged children at Elmaraghah Center in Sohag Governorate, also to identify the role of different risk factors associated in aetiology of asthma.
\end{abstract}

Patients and Methods: This cross sectional survey study, was conducted on 1796 children, (897 males and 899 females) from six to twelve years old in public primary schools in Elmaraghah center in Sohag governorate, all patient groups were exposed to questionnaire adopted from (ISAAC).

Results: The prevalence of asthma between children included in the current study was (12.5\%). Atopic dermatitis, food allergy, drug allergy, passive smoking and family history were related to high prevalence of bronchial asthma.

Conclusion: The prevalence of asthma was $12.5 \%$, and allergy to food and drugs is the most important risk factor of bronchial asthma.

Key Words: Prevalence - Bronchial asthma-Allergy - Atopy - Risk factors.

\section{Introduction}

ASTHMA and wheezes are the most common acute and chronic illness in children [1]. Asthma affects 300 million persons worldwide and may increase to 400 million persons worldwide by 2025 . Bronchial asthma leads to 250.000 dead cases every year that is a great socioeconomic challenge around the world [2]. The prevalence of asthma and allergies increases in developed and developing countries, despite the aetiology and risk factors of

Correspondence to: Dr. Abdelakher A. Rashied, E-Mail: abdela5er@gmail.com the conditions remain not understood [3]. Simple techniques for screening and measurement of the prevalence of childhood asthma, allergic rhinitis, and atopic eczema have been developed by many global organization as Global Initiative for Asthma GINA and the International Study of Asthma and Allergies in Childhood ISAAC. These methods are used for worldwide screening, assessment, and collecting data about prevalence of asthmain between different geographical areas and races. In our developing countries, asthma is common and varies in severity and affects our socioeconomic level so we should focus on screening and reporting the cases all over the country to minimize its side effects on individuals and society.

\section{Patients and Methods}

\section{Patients:}

Type of the study: Cross sectional survey study.

Duration: It was carried out from February 2018 to April 2018.

Inclusion criteria: Children in public primary schools, and their ages range from 6-12 years old.

Exclusion criteria: Children in the public primary schools younger than 6 years old and older than 12 years old.

Method of data collection: The questionnaire adopted from the international study of asthma and allergies in childhood organization, and it was translated into Arabic by Zedan, et al., [4] . It was self-administered and would be filled by the chidren or their parents in case of young aged children. 
Study design: This study was carried out in public primary schools in Elmaraghah center in Sohag governorate during the period from February to April 2018.

Target group: Public primary school children in Elmaraghah center.

Sample size: The sample size was to be calculated 2229, with the power of the study $80 \%, 95 \%$ Confidence Interval (CI), population size of the public primary school children in Elmaraghah center 68.000 , the prevalence of asthma is $12.5 \%$.

Sampling technique: The sample was selected by multistage sampling.

Simple random sampling: We choose three schools from Elmaraghag city, these were Mohammed Abdelmotaleb School, Fazarah School, andNagh-Elarab School from 59 school. Then by cluster sample type; we take all the children in each school.

Data source: Self-reported cases, the children would fulfil the questionnaire by themselves or by asking help of their parents.

Tools of data collection: Questionnaire adopted from the international study of asthma and allergies in childhood organization and translated into Arabic by Zedan, et al. [4], which included:

1- Personal information of the child as his name, gender, age, weight, and his school name.

2- Did the doctor diagnose you as asthmatic?

3- How many times you had asthma attacks per year?

4- Does the child get better after bronchodilators?

5- Which of the following symptoms did you have during flu attacks; wheezes, snoring, difficult breathing, tachypnea, asphyxia, fatigue, chest pain.

6- Do you have a family member who had asthma or under bronchodilators?

7- Do you have allergy to food or drugs?

8- Do you have atopic dermatitis or eczema?

9- Do you have smokers in your family?

\section{Criteria of case definition [5]:}

Confirmed cases; not applicable; confirmation is usually by laboratory investigation, so there are no confirmed cases for self-reported cases. Probable cases; lifetime asthma: If "Yes" to "Did a doctor ever tell you that you had asthma?" Current asthma: If "Yes" to "Did a doctor ever tell you that you had asthma?" and do you still have asthma? Possible cases; those had some of the clinical features.

\section{Results}

The current study found that the prevalence of asthma is $12.5 \%$ in Elmaraghah center in Suhag governorate among the school aged children as shown in (Table 1). Also we can find that doctor diagnosed asthma was $65.3 \%$ from the total asthmatics and wheezes with response to bronchodilators was $34.7 \%$ and the confirmed asthmatics wasn't applicable in self-reported data as shown in (Table 2).

From (Table 3); males had 1.1 times risk of developing asthma than females; with $p$-value 0.34 . Children who live in rural areas had 1.5 times risk of developing asthma than who live in urban areas, with $p$-value 0.012 . 6-8 years old children had 1.5 times risk of developing asthma than 11-12 years old children, with $p$-value 0.06 and 9-10 years old children had 1.1 times risk of developing asthma than $11-12$ years old children, with $p$-value 0.05 . Children who are allergic to food or drugs had 6.3 times risk of developing asthma than who don't, with $p$-value $<0.001$. Children who have atopic dermatitis had 2.6 times risk of developing asthma than who haven't, with $p$-value $<0.001$. Children who are exposed to smoking had 1.7 times risk of developing asthma than who isn't, with $p$-value $<0.001$ of developing asthma than who haven't, with $p$-value $<0.001$.

Table (1): Prevalence of bronchial asthma among school aged children in Elmaraghah Center in Sohag governorate.

\begin{tabular}{llc}
\hline Prevalence of asthma & No. & Percent \\
\hline Asthmatics & 225 & 12.5 \\
Non asthmatics & 1571 & 87.47 \\
\hline Total sample & 1796 & 100.0 \\
\hline
\end{tabular}

Table (2): Distribution of cases according to case definition.

\begin{tabular}{lll}
\hline Case definition & No. & Percent \\
\hline Confirmed & 0 & 0.0 \\
Probable & 147 & 62.3 \\
Possible & 78 & 34.7 \\
\hline Total & 225 & 100.0 \\
\hline
\end{tabular}


Table (3): Risk factors of bronchial asthma among school aged children in Elmaraghah Center in Sohag governorate.

\begin{tabular}{|c|c|c|c|c|}
\hline \multirow{2}{*}{$\frac{\text { Risk factor }}{\text { Sex: }}$} & \multicolumn{2}{|c|}{ No./225 Percent } & \multirow[t]{2}{*}{ OR (CI 95\%) } & \multirow[t]{2}{*}{$p$} \\
\hline & & & & \\
\hline Male & 119 & 13.3 & & 0.34 \\
\hline Female & 106 & 11.8 & $(0.86-1.42)$ & \\
\hline \multicolumn{5}{|c|}{ Residence: } \\
\hline Rural & 171 & 13.9 & 1.5 & 0.012 \\
\hline Urban & 54 & 9.6 & $(1.19-1.82)$ & \\
\hline \multicolumn{5}{|l|}{ Age: } \\
\hline 6-8 & 41 & 15.8 & $1.5(0.98-2.21)$ & 0.06 \\
\hline $9-10$ & 103 & 12.6 & $1.1(0.83-1.45)$ & 0.05 \\
\hline $11-12$ & 81 & 11.3 & 1.0 & \\
\hline \multicolumn{5}{|l|}{$\begin{array}{l}\text { Allergy to } \\
\text { food/drugs: }\end{array}$} \\
\hline Yes & 91 & 37.4 & 6.3 & 0.000 \\
\hline No & 134 & 8.6 & $(6.03-6.65)$ & \\
\hline \multicolumn{5}{|c|}{ A topic dermatitis: } \\
\hline Yes & 96 & 21.5 & 2.6 & 0.000 \\
\hline No & 129 & 9.6 & $(2.30-2.88)$ & \\
\hline \multicolumn{5}{|c|}{ Passive smoking: } \\
\hline Yes & 143 & 15.7 & & 0.000 \\
\hline No & 82 & 9.2 & $(1.37-1.94)$ & \\
\hline \multicolumn{5}{|c|}{ Family history: } \\
\hline Positive & 100 & 28.5 & 4.2 & 0.000 \\
\hline Negative & 125 & 8.7 & $(3.91-4.50)$ & \\
\hline
\end{tabular}

\section{Discussion}

In this study, we found that the prevalence of asthma is $12.5 \%$. As there are wide variety of prevalence of asthma, in Cairo it was found that prevalence of asthma was $9.4 \%$ [6]. In the Nile Delta, ISAAC based study on 3410 children, found that the prevalence of asthma was $7.7 \%$ [4]

In Suhag University Hospital, self-administered questionnaire applied on 3-12 years old children who presented to the clinics in 2010, total of 12612 children out of them $1.4 \%$ were doctor diagnosed asthmatics [7]. We depend on the case definition of surveillance of the bronchial asthma from [5], and found that $8.2 \%$ are probable cases and $4.3 \%$ are possible cases in Elmaraghah Center in Suhag governorate.

We found that males had 1.1 times risk of developing asthma than females, as there was $13.3 \%$ of males and $11.8 \%$ of females are asthmatic. In Elmenofia, insignificant effect of gender on prevalence of asthma, as it was in males and females $13 \%$ \& $12.5 \%$ respectively [8]. Previous study in Mansoura found that $8.6 \%$ of males and
$6.9 \%$ of females were asthmatic [4]. In USA, study reported that among children aged 0-17 years old boys have a higher prevalence $11.3 \%$ than girls $7.9 \%$ [9].

Children who lives in rural area had 1.5 times risk of developing asthma than who lives in urban area. In Oropeza-Province, Bolivia, ISAAC standardized questionnaire was applied to 2584 children who seem to have a higher prevalence of symptoms of asthma in rural area compared to urban area; $12.4 \%$ and $9.2 \%$ respectively [10]. In El-Minofiya, cross sectional study reported that the prevalence of asthma was $14 \%$ in urban area and $7.1 \%$ in rural area $[8]$, in Suhag University Hospital. From the pediatric clinics urban vs rural 1:3 $p<0.001$ [7].

The younger age the higher prevalence of asthma, $p$-value $=0.06$. In USA, children aged 0-17 years had higher asthma prevalence $9.5 \%$ than adults aged 18 and over $7.7 \%$ for the period 20082010 [9]. In Cheonan, Korea, the prevalence of asthma symptoms decreased by increasing age $16.5 \%, 9.8 \%, 6.5 \%, 5.4 \%$ for $0-3,4-6,7-9$ and 10 13 year old children respectively [10] . In Egypt, asthma prevalence in younger children is higher than older children [11]. Is Asyut, Egypt, a study divides the sample from the preparatory schools as $>15$ and $<15$ and reported that Asthma was not associated with age [12].

Children who are allergic to food or drugs had 6.3 times risk of developing asthma than who don't, with $p$-value $<0.001$ and children who have atopic dermatitis had 2.6 times risk of developing asthma than who haven't. And this is the most important related risk factor of asthma. In New York, significant relation between allergy to food and prevalence of asthma with odd ratio 2.3 and $p$-value $<0.001$ [13]. In Denizli, Turkey, a study reported family history of atopy increase the risk for all symptoms of asthma [14]. Family history of allergy and bad housing were documented as risk factors associated with prevalence of asthma in Egypt and The related risk factors for the prevalence of asthma in Turkey were reported to be family history of atopy [11]. In Africa, a study told us that exposure to common allergens has all been implicated as triggers of asthma [15], in Mansoura, Egypt, a study reported that history of atopy was an associated risk factor with asthma [4]. In Dakahlia, a study reported that history of atopy was significantly correlated with asthma [16]

Children who exposed to smoking had 1.7 times risk of developing asthma than who isn't. In Korea, 
a study reported that children who exposed to passive smoking had 2 times risk of developing asthma more than not exposed children, and in New-Zeeland the odd ratio was 1.2 [17]. In Turkey, high prevalence of asthma was in relation to high rate of passive smoking as $49.3 \%$ of children had smoking parents [18]. In the Delta region, Egypt, study reported a relation between asthma and passive smoking $\mathrm{OR}=1.3$ and $p$-value $>0.05$ [4] .

Children who have positive family history of asthma had 4.2 times risk of developing asthma than who haven't. In Saskatchewan, Canada, there was a high prevalence of early respiratory illness, related with positive family history of asthma [19] In Hangzhou, china, family history is a risk for asthma $p$-value <.001 [20]. In Al-Ain, UAE, family history of asthma was the strongest predictor of asthma with an OR 3.75 [21]. At Ismailia, there is a strong correlation between family history of asthma and prevalence of asthma [22]. In Asyut, family history of asthma was significantly related to asthma among the asthmatic students $p$-value $<0.0001[12]$

\section{Study limitation:}

Awareness level plus ignorance of some low socioeconomic families are the problems that we have met in this surveillance study.

\section{References}

1- ASHER I. and PEARCE N.: Global burden of asthma among children. The International Journal of Tuberculosis and Lung Disease, 18 (11): 1269-78, 2014.

2- PRICE A.L., PATTERSON N.J., PLENGE R.M., WEINBLATT M.E., SHADICK N.A. and REICH D.: Principal components analysis corrects for stratification in genomewide association studies. Nature Genetics, 38 (8): 9049, 2006.

3- BEASLEY R., CRANE J., LAI C.K. and PEARCE N.: Prevalence and etiology of asthma. The Journal of Allergy and Clinical Immunology, 105 (2 Pt 2): S466-72, 2000.

4- ZEDAN M., SETTIN A., FARAG M., EZZ-ELREGAL M., OSMAN E. and FOUDA A.: Prevalence of Bronchial Asthma Among Egyptian School. Egyptian Journal of Bronchology, 3 (2): 124-30, 2009.

5- SAMUEL L. GROSECLOSE, ROBERT R. GERMAN and PETER NSUBUGA: Evaluating Public Health Surveillance, Oxford Scholarship Online, 17-20, 2010.

6- GEORGY V., FAHIM H.I., EL GAAFARY M. and WALTERS S.: Prevalence and socioeconomic associations of asthma and allergic rhinitis in northern Africa. European Respiratory Journal, 28 (4): 756-62, 2006.

7- ELMONEIM A.A., HASSAN I.A., ELNABY A.A. and ELMAGD A.A.: Epidemiology and outcome of childhood asthma: A clinical study in an Egyptian university medical centre, 19 (6): 520-6, 2013.

8- ALI A., SALLAM M.M., FATHY G.A., MOHY EL DIN O., AWAD S.A. and AHMED A.: Epidemiological Study of the Prevalence of Bronchial Asthma and Other Atopic Diseases Among School Children in Egypt. International Journal of Academic Research, 2 (4): 209-17, 2010.

9- AKINBAMI L.J., MOORMAN J.E., BAILEY C., ZAHRAN H.S., KING M., JOHNSON C.A. and LIU X.: Trends in Asthm a Prevalence, Health Care Use, and Mortality in the United States. NCHS Data Brief, (94), 2012.

10- TERESA M., SOTO S., PATIÑO A., NOWAK D. and RADON K.: Prevalence of asthma, rhinitis and eczema symptoms in rural and urban school-aged children from Oropeza Province-Bolivia: A cross-sectional study, 1621, 2014.

11- HONG S., SON D.K., LIM W.R., KIM S.H., KIM H., YUM H.Y. and KWON H.: The prevalence of atopic dermatitis, asthma, and allergic rhinitis and the comorbidity of allergic diseases in children. Environmental Health and Toxicology, 27: e2012006, 2012.

12- ALAVINEZHAD A. and BOSKABADY M.H.: The prevalence of asthma and related symptoms in Middle East countries. Clinical Respiratory Journal, 12 (3): 865-77, 2018.

13- ABDALLAH A.M.: Epidemiology of bronchial asthma among preparatory school children in Assiut district. Egypt J. Pediatr. Allergy Immunol., 10 (2): 109-17, 2012.

14- LIU A.H., JARAMILLO R., SICHERER S.H., WOOD R.A., BOCK S.A., BURKS A.W. and ZELDIN D.C.: National prevalence and risk factors for food allergy and relationship to asthma: Results from the National Health and Nutrition Examination Survey 2005-2006. Journal of Allergy and Clinical Immunology, 126 (4): 798-806.e14. 2010.

15- UGURLU E., ÖNCEL S.B. and EVYAPAN F.: Symptom prevalence and risk factors for asthma at the rural regions of Denizli, Turkey. Journal of Thoracic Disease, 6 (5): 452-8, 2014.

16- ADELOYE D., YEE K. and RUDAN I.: An estimate of asthma prevalence in Africa: WHO Collaborative Centre for Population Health Research and Traininga systematic analysis, 519-31, 2013.

17- MEATTY E.M., EL-DESOKY T., EL-DOMYATY H. and NASEF N.: Prevalence of childhood bronchial asthma and its associated factors: A community-based study in Egypt, 2 (2): 14-20, 2018.

15- COOK D.G. and STRACHAN D.P.: Parental smoking and prevalence of respiratory symptoms and asthma in school age children, (April), 1081-94, 1997.

19- BAYRAM I., GUNESER-KENDIRLI S., YILMAZ M., ALTINTAS D.U., ALPARSLAN N. and BINGOLKARAKOC G.: The prevalence of asthma and allergic diseases in children of school age in Adana in Southern Turkey. Turkish Journal of Pediatrics, 46 (3): 221-5, 2004.

20- LAWSON J.A., CHU L.M., RENNIE D.C., HAGEL L., KARUNANAYAKE C.P., PAHWA P. and DOSMAN 
J.A.: Prevalence, risk factors, and clinical outcomes of atopic and nonatopic asthmaamong rural children. Annals of Allergy, Asthma \& Immunology, 2016.

21- XU D., WANG Y., CHEN Z., LI S., CHENG Y., ZHANG L. and ZHAO L.: Prevalence and risk factors for asthma among children aged 0-14 years in Hangzhou: A crosssectional survey. Respiratory Research, 17 (1): 1-8, 2016.

22- ALSOWAIDI S., ABDULLE A. and BERNSEN R.: Prev- alence and Risk Factors of Asthma among Adolescents and Their Parents in Al-Ain (United Arab Emirates). Respiration, 79 (2): 105-11, 2010.

23- HALIM W., KHALIL K., SOBHY S. and HASABALLAH S.: Prevalence of Bronchial Asthma Among Secondary Schools Students At Abu Khalifa Village Ismailia Governorate. The Medical Journal of Cairo University, 81 (2): 19-24, 2013.

\section{دراسة حول إنتشار الريو بين آطفال المداربس بمركز المراغة محافظة سوهاج}

تعتبر آمراض حساسية الصدر وضيق الشعب الهوائية من آكثر الآمراض القصيرة والطويلة الآمد فى مرحلة الطفولة. ومن المهم الإكتشاف المبكر للمرض وكذلك علاجه ومتابعته لتقليل مخاطره ومضاعفاته المستقبلية. تهدف هذه الرسيالة إلى تقييم معدل إنتشار المرض الإضئ بين آطفال

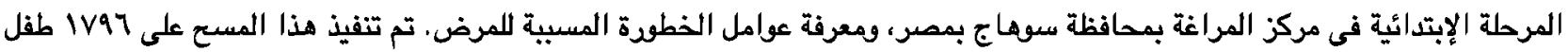

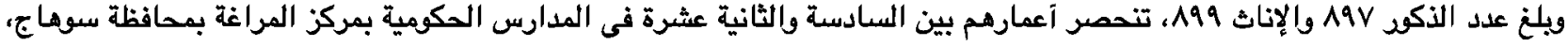

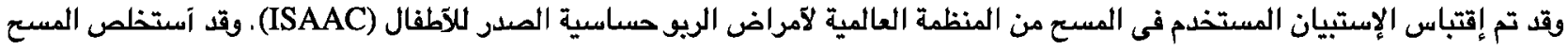

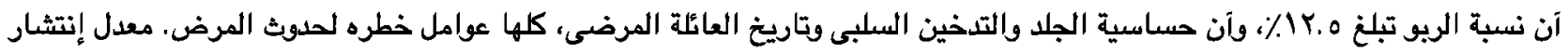

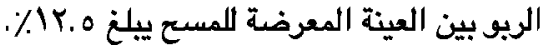

